\title{
Fernand OUELLET
}

Écrivain, historien et professeur québécois (1926-]

(1973)

\section{"Nationalisme canadien-français et laïcisme au XIXe siècle.”}

\author{
Un document produit en version numérique par Réjeanne Toussaint, ouvrière \\ bénévole, Chomedey, Ville Laval, Québec \\ Page web. Courriel: rtoussaint@aei.ca \\ Dans le cadre de la collection: "Les classiques des sciences sociales" \\ Site web: http://www.uqac.ca/Classiques_des_sciences_sociales/ \\ Une collection développée en collaboration avec la Bibliothèque \\ Paul-Émile-Boulet de l'Université du Québec à Chicoutimi \\ Site web: http://bibliotheque.uqac.uquebec.ca/index.htm
}




\section{Politique d'utilisation de la bibliothèque des Classiques}

Toute reproduction et rediffusion de nos fichiers est interdite, même avec la mention de leur provenance, sans l'autorisation formelle, écrite, du fondateur des Classiques des sciences sociales, Jean-Marie Tremblay, sociologue.

Les fichiers des Classiques des sciences sociales ne peuvent sans autorisation formelle:

- être hébergés (en fichier ou page web, en totalité ou en partie) sur un serveur autre que celui des Classiques.

- servir de base de travail à un autre fichier modifié ensuite par tout autre moyen (couleur, police, mise en page, extraits, support, etc...),

Les fichiers (.html, .doc, .pdf, .rtf, .jpg, .gif) disponibles sur le site Les Classiques des sciences sociales sont la propriété des Classiques des sciences sociales, un organisme à but non lucratif composé exclusivement de bénévoles.

Ils sont disponibles pour une utilisation intellectuelle et personnelle et, en aucun cas, commerciale. Toute utilisation à des fins commerciales des fichiers sur ce site est strictement interdite et toute rediffusion est également strictement interdite.

L'accès à notre travail est libre et gratuit à tous les utilisateurs. C'est notre mission.

Jean-Marie Tremblay, sociologue

Fondateur et Président-directeur général, LES CLASSIQUES DES SCIENCES SOCIALES. 
Cette édition électronique a été réalisée par Réjeanne Toussaint, bénévole,

Courriel: $\underline{\text { toussaint@aei.ca }}$

à partir de :

Fernand Ouellet

“Nationalisme canadien-français et laïcisme au XIXe siècle.”

Un article publié dans l'ouvrage sous la direction de Jean-Paul Bernard, Les idéologies québécoises au $19^{e}$ siècle, pp. 37-60. Montréal : Les éditions du boréal express, 1973, 151 pp. collection : Études d'histoire du Québec, no 5.

Polices de caractères utilisée :

Pour le texte: Times New Roman, 12 points.

Pour les citations : Times New Roman, 12 points.

Pour les notes de bas de page : Times New Roman, 12 points.

Édition électronique réalisée avec le traitement de textes Microsoft Word 2008 pour Macintosh.

Mise en page sur papier format : LETTRE (US letter), 8.5’’ x 11'’)

Édition numérique réalisée le 27 juillet 2010 à Chicoutimi, Ville de Saguenay, province de Québec, Canada.

\section{Fait avec}

Macintosh 


\section{Fernand OUELLET}

Écrivain, historien et professeur québécois (1926-]

\section{"Nationalisme canadien-français et laïcisme au XIXe siècle.”}

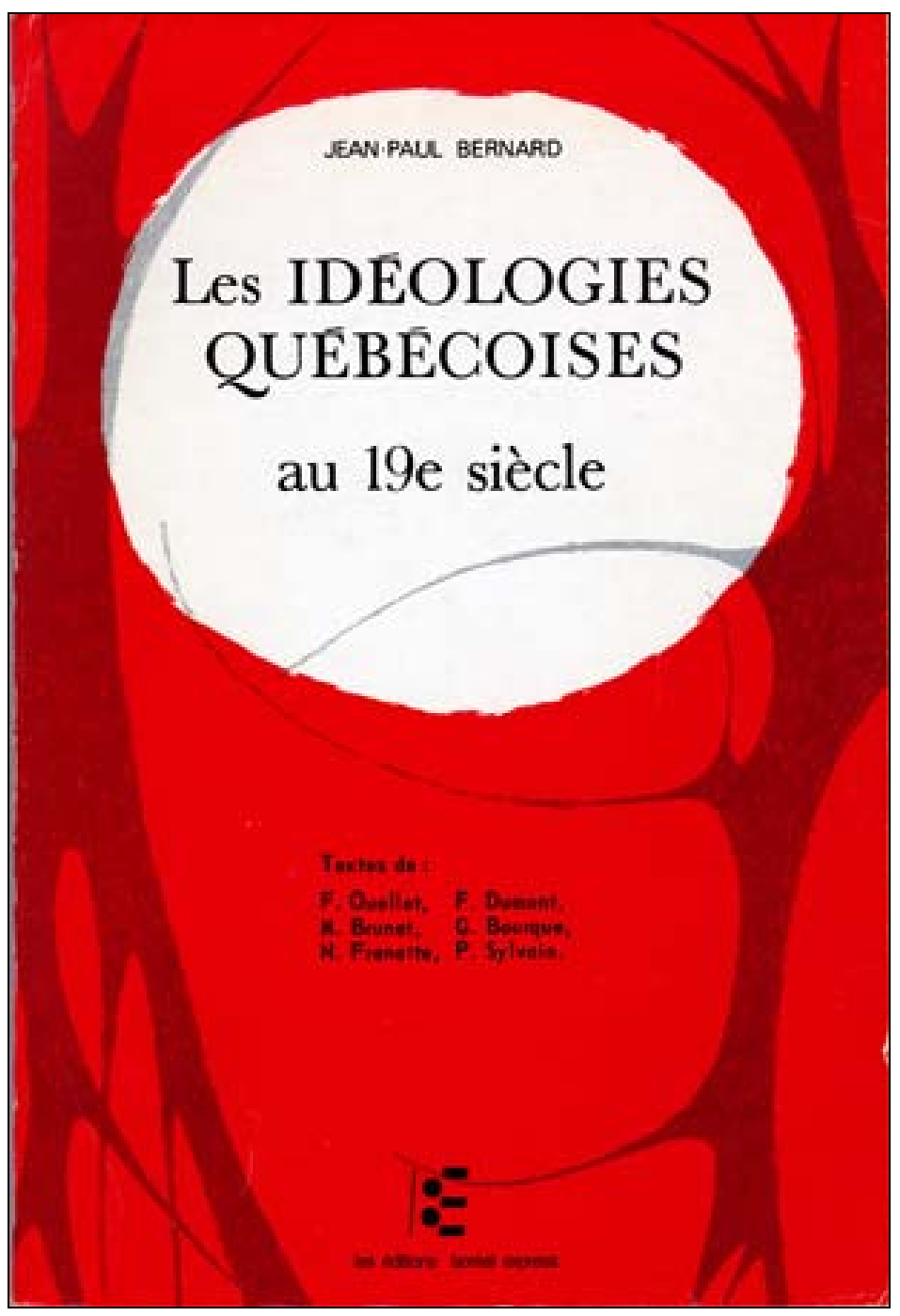

Un article publié dans l'ouvrage sous la direction de Jean-Paul Bernard, Les idéologies québécoises au 19 ${ }^{e}$ siècle, pp. 37-60. Montréal : Les éditions du boréal express, 1973, 151 pp. collection : Études d'histoire du Québec, no 5. 


\section{Table des matières du livre}

Jean-Paul Bernard, “Présentation”. [pp. 7-35.]

Fernand Ouellet, "Nationalisme canadien-français et laïcisme au XIXe siècle.” [pp. 37-60.]

Fernand Dumont, ”Idéologie et conscience historique dans la société canadienne-française du XIXe siècle”. [pp. 61-82.]

Michel Brunet, "L'Église catholique du Bas-Canada et le partage du pouvoir à l'heure d'une nouvelle donne (1837-1854)." [pp. 83-97.]

Gilles Bourque et Nicole Frenette, "La structure nationale québécoise (extraits).” [pp. 99-126.]

Philippe Sylvain, ”Quelques aspects de l'antagonisme libéral-ultramontain au Canada français.” [pp. 127-149.] 


\section{Table des matières}

I. La faillite du laïcisme à l'époque des patriotes

II. L'affirmation du nationalisme ultramontain 


\author{
Fernand Ouellet \\ Écrivain, historien et professeur québécois (1926-] \\ "Nationalisme canadien-français \\ et laïcisme au XIXe siècle”. *
}

Un article publié dans l'ouvrage sous la direction de Jean-Paul Bernard, Les idéologies québécoises au $1^{e}$ siècle, pp. 37-60. Montréal : Les éditions du boréal express, 1973, 151 pp. collection : Études d'histoire du Québec, no 5.

Retour à la table des matières

Le nationalisme canadien-français a eu la réputation d'avoir fait mauvais ménage avec tous les courants de pensée et tous les mouvements susceptibles de promouvoir une société laïque dans le Québec. Son allergie passée au capitalisme, au libéralisme, à la démocratie et aux tendances socialisantes relève pour une large part de cette problématique. Son absence d'affinités avec le capitalisme commercial et industriel ne venait-elle pas en dernier ressort de ce que la bourgeoisie fût pendant longtemps dans d'autres sociétés le principal moteur, avec les intellectuels, du laïcisme ? Quant au libéralisme, son caractère essentiellement laïque et bourgeois n'avait rien de bien rassurant pour une idéologie qui fondait ses valeurs sur la terre et l'Église. Il en est ainsi de la démocratie, formule assise sur le droit naturel, sur la souveraineté populaire, plutôt que sur le droit divin des rois et les privilèges des classes. Enfin, si le nationalisme canadien-français parut aussi obstinément fermé au renforcement de l'appareil étatique, c'est certainement parce que l'État pouvait représenter, au même titre que la bourgeoisie, un des véhicules les plus puissants du laïcisme. Par contre, le nationalisme canadien-français ne s'est-il pas plus spontanément lié au cléricalisme, à l'ultramontanisme, aux idéaux théocratiques et, pour employer une expression chère à M. Michel Brunet, à

* Texte paru dans Recherches sociographiques, IV, 1 (janvier-avril 1963) : 4770. Reproduit avec la permission des Presses de l'Université Laval. 
l'agriculturisme ? Ces caractéristiques presque actuelles d'un nationalisme éminemment conservateur, voire même réactionnaire, apparaissent davantage comme l'aboutissement d'une évolution, pleine à certains moments de sursauts et de contestations, que comme une donnée inscrite d'emblée à l'origine de notre nationalisme.

Même si, depuis le début du XIXe siècle, le nationalisme canadien-français paraît avoir été en conflit ouvert avec toutes les idéologies porteuses de laïcisme, il n'en est pas moins vrai que cette confrontation n'a pas toujours abouti à un rejet en bloc. On peut même évoquer, si on en juge par les dehors ou par les tiraillements des consciences, quelques moments importants ou s'exprime une association assez étroite avec le libéralisme et la pensée démocratique.

[38] Le parti canadien et son successeur légitime, le parti patriote, ne prétendaient-ils pas au titre de libéral et de démocratique ? Reste à connaître cependant les rapports réels qui existaient entre le nationalisme des patriotes et leur laïcisme. Autrement dit, existe-t-il avant 1837 un mouvement laïc possédant une certaine autonomie ? Dans quelle mesure le nationalisme dit libéral ou démocratique accordait-il la prééminence aux libertés individuelles sur les droits collectifs ? Ne s'agissait-il pas en fin de compte, plutôt que d'un nationalisme libéral ou démocratique, d'un national-libéralisme n'utilisant par conséquent les idées nouvelles que pour mieux atteindre certains objectifs proprement conservateurs ? Après les travaux faits sur cette période, il existe encore beaucoup d'obscurité et de confusion autour des croyances et des attitudes de ceux qui furent à l'origine de notre première aventure séparatiste. Aussi importe-t-il de ne pas se laisser aveugler par le panache, par les déclarations sonores, de ne pas prendre le mythe pour la réalité. Il reste cependant que l'échec des insurrections de 1837-38 a donné un dur coup au mouvement laïc.

Après 1837, pendant que le nationalisme s'identifie de plus en plus, en dépit des options multiples qu'il recouvre, au cléricalisme et à l'ultramontanisme, s'affirme un mouvement d'essence proprement libérale. Ne au cours de la décennie 1840-50, l'Institut canadien de Montréal mène pendant vingt-cinq ans une lutte acharnée en faveur du laïcisme. Puis, au moment même où, dans l'affaire Guibord, il venait de remporter une éclatante victoire légale, il doit s'effacer. À l'heure de Mgr Bourget, suffit-il que Londres soit d'accord pour que le Québec le devienne ? Puis, le siècle se termine avec les luttes pour la reconnaissance du parti 
libéral. La encore les forces de l'ordre, de la tradition, de la conformité aux valeurs établies l'ont emporté haut la main. Comment expliquer ces défaites successives du mouvement libéral et des tendances laïques ?

\section{I \\ La faillite du laïcisme à l'époque des patriotes}

$\underline{\text { Retour à la table des matières }}$

Le courant laïc avait eu ses sources dans l'effort des intellectuels et de la bourgeoisie qui, depuis la Renaissance, avaient oeuvré afin d'asseoir les bases d'une société nouvelle. Déjà, l'École du droit naturel et certains penseurs politiques étaient parvenus à libérer la science politique de ses fondements théologiques traditionnels. Au XVIIIe siècle, la bourgeoisie et les philosophes adhèrent en masse à une morale naturelle et laïque dégagée de celles des religions révélées. Non seulement ils contestent les fondements théoriques de la monarchie de droit divin, mais ils affirment la primauté absolue des libertés individuelles. Aussi la Révolution française apparaît-elle comme l'oeuvre d'une bourgeoisie désireuse d'inscrire dans les [39] faits une conception individualiste et laïque de la société. La Déclaration des droits de l'homme est l'expression directe de cette vision des choses centrée sur la nécessité de protéger désormais, par des structures adéquates, les droits individuels et d'éliminer les privilèges du clergé, de la noblesse et des corporations, obstacles à l'essor du capitalisme industriel et de la société bourgeoise. Le Canada de la fin du XVIIIe siècle était-il prêt à consacrer chez lui cette évolution globale ? N'en était-il pas encore, en raison de ses structures sociales, de sa situation économique et de ses conceptions politiques, aux influences partielles ? Il y a bien à la fin du XVIIIe siècle un petit courant voltairien ${ }^{1}$ mais, dans l'ensemble, rien qui mobilise une élite comme telle. Si, dans les milieux britanniques, les croyances politiques et sociales favorisent un juste équilibre entre le

1 Marcel TRUDEL, L'influence de Voltaire au Canada de 1760 à 1850, Montréal, Fides, 1945, vol. I. 
principe monarchique, le principe aristocratique et le principe démocratique, il n'en est pas ainsi parmi la population canadienne-française toujours attachée à la monarchie absolue de droit divin, au gallicanisme ou à l'esprit théocratique. Baillargé aura beau définir l'introduction du parlementarisme comme le premier jour de liberté au Canada ${ }^{2}$; un adolescent en rupture avec sa famille, Henri de Mézières, aura beau entonner l'hymne du républicanisme, il ne s'agit la que de témoignages isoles sans portée profonde. Le voltairianisme et l'esprit de l'Encyclopédie ne rejoignent encore que les couches superficielles de la conscience des élites. Le Canada du temps reste plus près de Bossuet que de Montesquieu et de Rousseau. On pourrait même affirmer que le Québec de la fin du XVIIIe siècle est plus mur pour la réaction que pour l'acceptation de cette évolution nouvelle. Ainsi, la croyance au «bon sauvage » qu'on observe chez J.-B. Trudeau, explorateur du Haut-Missouri, n'est pas le signe d'une adhésion globale à la philosophie du XVIIIe siècle. ${ }^{3}$

La société canadienne-française d'alors possède toutes les caractéristiques d'une société d'Ancien Régime, hormis toutefois la présence bienfaisante d'une grande bourgeoisie d'affaires, la seule qui aurait pu servir de moteur efficace au laïcisme. À sa tête, on trouve le clergé. Certes, ce dernier souffre d'une grande pénurie de membres, mais son influence morale sur la population n'en est pas moins décisive. Grand propriétaire terrien, il exerce par l'entremise du régime seigneurial une autorité supplémentaire sur ses tenanciers. Par la paroisse et la famille, institutions communautaires qui ont pris le pas sur la seigneurie et le village, les curés dirigent la vie religieuse et même temporelle de leurs paroissiens. Ainsi, le curé Fournier prétendra sans vantardise être le maître absolu dans sa paroisse ; il ne s'agit pas là d'une affirmation gratuite, il en produira des [40] preuves irréfutables. ${ }^{4}$ Au reste, les évêques déploreront de temps à autre la propension des curés à régler leurs querelles personnelles en chaire, ce qui montre une tendance à confondre ce qui relève de la religion et ce qui est strictement pro-

2 Musée de la Province, Journal de François Baillargé : «1792 est la première année libre de ce pays » (p. 127).

3 Archives du Séminaire de Québec, Journal de... J.-B. Trudeau.

4 L'abbé V.-C. Fournier à Mme Morett (20 juil. 1817) : Bulletin des recherches historiques, XVII, 14. 
fane. ${ }^{5}$ Les évêques déploreront au surplus le goût des curés pour les gros presbytères semblables, ajoute un évêque, à des manoirs féodaux. ${ }^{6}$ Tout cela indique la présence rassurante dans ce Québec du début du XIXe siècle de l'Église-société. C'est que le clergé détient effectivement le monopole de l'enseignement qui, au niveau primaire, est assumé dans beaucoup de cas par des laïcs. Mais nous ne sommes pas pour autant en plein laïcisme. Il en est ainsi de l'hospitalisation.

Au sommet de la société se trouve également l'aristocratie foncière traditionnelle, celle des seigneurs, qui elle aussi apparaît des plus conservatrices. Mais cette classe n'a cessé, en raison de son manque de dynamisme, de décliner et cela depuis 1760. Le gouvernement, inspiré du désir de maintenir l'influence aristocratique dans le pays, fera des efforts infructueux pour redorer le blason de cette noblesse décadente. Le traditionalisme profond de ces deux classes les empêche de se rallier à ce qui fait l'essence de la liberté britannique et au parlementarisme. L'évêque de Québec n'acceptera finalement le régime parlementaire que parce qu'il lui promettait plus de facilités dans le recrutement de prêtres français. ${ }^{7}$ D'ailleurs, Mgr Plessis ne concevra jamais la Chambre d'Assemblée autrement que comme un organisme consultatif. Cette vision des choses a une certaine teinte maurassienne. ${ }^{8}$

La révolution française a eu pour effet de déclencher un mécanisme de défense chez les élites canadiennes. Évidemment, c'est la lutte contre les idées démocratiques qui s'organise tant au niveau du gouvernement que des classes dirigean-

5 Mgr Lartigue à Mgr Plessis (1er oct. 1825), Rapport de l'Archiviste de la province de Québec pour 1941-42 (RAPQ) : " Que c'est un mal général et invétéré dans son district que les prêtres fassent un usage sacrilège de la chaire pour y venger leurs querelles partilières » (p. 467).

6 Mgr Lartigue à Mgr Signay (29 déc. 1835), RAPQ, 1943-44, 333. Il ne veut pas que l'église de Sainte-Marie se charge de payer la rente de 800 louis que coûtera la maison qui servira de presbytère : "Cette maison trop élégante et luxueuse pour un prêtre donnera le mauvais exemple à nos curés trop enclins à l'érection de presbytères fastueux, qui ont l'air de manoirs seigneuriaux. » La réaction de l'évêque se comprend aussi en regard de la crise agricole.

7 Mgr Plessis a Mgr Lartigue (13 sept. 1823) : Archives de l'Archevêché de Québec, Registre des 1ettres, vol. Il, 280 et suiv.

8 Voir notre article : « Mgr Plessis et la naissance d'une bourgeoisie canadienne (1797-1810) », Rapport 1956, La Société canadienne d'Histoire de l'Église catholique, 83-100. 
tes. Aux yeux des Britanniques, la Révolution française, avec ses tendances républicaines, menace la liberté anglaise ; aux yeux des dirigeants canadiens-français, ce sont l'Église et les traditions aristocratiques qui sont en péril. Aussi, le clergé et la noblesse mènent-ils une lutte [41] sans rémission contre toutes les manifestations de libre-pensée. À plusieurs occasions importantes, Mgr Plessis éprouvera le besoin de condamner sans appel les idées libérales et d'exposer aux fidèles la théorie de la monarchie de droit divin comme les motifs de la soumission inconditionnelle qu'ils doivent au pouvoir établi. Pourtant, le Canada du temps était doté d'institutions parlementaires et on parlait des droits du citoyen britannique. Même si on décèle chez l'évêque de Québec certaines tendances théocratiques, au reste plus pratiques que doctrinales, renforcées à la fin de son épiscopat par la lecture des livres de J. de Maistre et de Bonald, Mgr Plessis demeure néanmoins fidèle aux conceptions gallicanes du pouvoir politique.

La réaction catholique et monarchique n'aurait pas tellement eu sa raison d'être, du moins elle n'aurait pas eu la force qu'elle a manifestée, si au cours des dix années qui ont suivi l'implantation du système parlementaire, le levain du libéralisme n'avait germé dans certains secteurs de la société canadienne-française. ${ }^{9}$ Que, vers 1830, un seigneur et une grande bourgeoise s'amusent à discuter des mérites respectifs de l'éducation traditionnelle et des théories de Rousseau et de Locke en cette matière, c'est là un signe des temps, mais c'est aussi une coquetterie de salon dont on ne peut postuler la profondeur. ${ }^{10}$ D'ailleurs, la réponse du seigneur règle le problème de l'éducation de l'enfant : une bonne fessée arrange tout. Aussi n'est-ce pas dans l'aristocratie terrienne qu'est apparu le danger libéral, en particulier celui du laïcisme. Celle-ci est encore trop tributaire de l'Église-

9 « [Au temps de Mgr Briand] il y avait plus de respect pour le clergé et moins d'yeux ouverts pour observer ses démarches. Les fidèles étaient plus dociles et encore à l'abri des effrayants progrès qu'ont faits dans leurs esprits les principes de liberté et de démocratie propagés par notre nouvelle constitution, par l'exemple contagieux de la Révolution française ». Mgr Plessis à J. Panet, curé de Lislet (30 déc. 1815) ; RAPQ, 1928-29, 112.

10 Lettre de Mme Bercy au chevalier (I'Estimauville (14 juil. 1830) ; lettre du même à la même (16 juil. 1830) : APQ, lettres diverses (1748-1869) ; copies. Mme Bercy, une Panet, prend les choses beaucoup plus au sérieux que le chevalier. Parlant de l'éducation familiale traditionnelle et de son expérience chez les Dames de la Congrégation, elle dit : l'éducation « que mes compatriotes donnaient à leurs enfants était des plus vicieuses... » 
institution, des valeurs monarchiques et aristocratiques pour devenir l'inspiratrice d'un mouvement laïque.

Le Canada français de la fin du XVIIIe siècle a vu se développer, à la faveur de l'expansion démographique et du progrès économique, une moyenne bourgeoisie composée des professions libérales et des petits marchands des villes et des campagnes. Issus en majorité du milieu paysan, ces hommes de profession et ces petits boutiquiers n'en aspirent pas moins au début du XIXe siècle à remplacer les seigneurs comme élite laïque de leur société. En rupture avec les valeurs aristocratiques - du moins elle le prétend -, cette bourgeoisie cherche, plus ou moins confusément au début, à asseoir la société sur des bases nouvelles. Mgr Plessis, qui assista à la naissance de ce phénomène, a très vite compris le danger qu'il représentait pour la société traditionnelle. Il en sera de même des curés de campagne [42] qui, avec l'arrivée des notaires, des médecins et des arpenteurs dans les paroisses, verront leur leadership contesté. Les hommes de profession vont se heurter au clergé non seulement dans leur effort de promotion sociale mais même, dans de nombreux cas, dans leur activité propre. Qu'on songe aux difficultés du médecin qui cherche à s'imposer dans un milieu où ses responsabilités avaient été assumées jusque là par les guérisseurs magiques et les curés. Dans les villes, l'attitude de l'Église canadienne à l'égard du prêt à intérêt et des banques paraît avoir beaucoup affecté les marchands, les avocats et les notaires. Mgr Plessis prétendra que la majorité des avocats ont cessé de fréquenter les sacrements en raison de l'intransigeance de ses principes sur la question du prêt à intérêt. 11 En beaucoup d'autres domaines, cette jeune bourgeoisie, encore mal adaptée certes à son nouveau statut mais éveillée a certaines valeurs bourgeoises, aura à souffrir des cadres ecclésiaux traditionnels trop rigides pour lui permettre de s'épanouir. L'incompréhension entre l'Église canadienne et cette bourgeoisie sera encore beaucoup plus marquée au niveau politique.

11 Sur la question du prêt à intérêt et de la désaffection religieuse de cette élite, voir : Mgr Plessis grand-vicaire Bourret (15 mai 1807) : Saberdache bleue, vol. II, 294 et suiv. Sur les banques : «Parce ne tous les banquiers de cette province sont usuriers, en retenant sans aucun risque l'intérêt au moment même du prêt ». Mgr Lartigue à Mgr Turgeon (22 janv. 1837) : RAPQ, 1944-45, 230. 
Dans le passé, le clergé et la noblesse avaient édifié leur prestige sur leur influence morale et sur la propriété foncière. Mais cette nouvelle bourgeoisie n'avait que très peu de choses qui lui garantissent une pareille reconnaissance sociale. À partir du début du XIXe siècle, elle ne peut même pas aspirer à la richesse par sa propre activité professionnelle. C'est le moment où l'agriculture du Québec entre dans une phase longue de crise qui a pour effet de réduire les revenus paysans et, conséquemment, ceux des hommes de profession et les profits des commerçants. Pourtant, les effectifs des professions libérales continuent à croître a un rythme inquiétant au point que la majorité de leurs membres ne verront d'autre issue que la politique. La politique, aux yeux de la plupart de ceux qui s'y engageaient, devait leur procurer la stabilité financière et le prestige social. Ce fut le cas de Pierre Bédard et ce sera celui de Papineau. La nature même du parlementarisme canadien favorisait nettement l'accès des hommes de profession à l'action publique. Point n'était besoin d'être riche pour voter et devenir député. Même si l'Angleterre avait appliqué au Canada le principe du suffrage censitaire, elle avait fait montre d'une telle libéralité dans la définition du cens électoral qu'il s'agissait en définitive d'un suffrage quasi universel. Cette politique contrastait singulièrement avec celle qui avait cours en Angleterre où seule une minorité avait le droit de vote. Aussi les institutions parlementaires deviennent-elles, au début du XIXe siècle, le moyen par excellence emprunté par les hommes de profession canadiens-français pour s'édifier en élite laïque de leur société.

[43] On aurait pu s'attendre à ce que cette bourgeoisie, comme partout ailleurs, liât son avenir à celui de la bourgeoisie capitaliste anglaise. La croyance en des valeurs communes tant sur le plan politique que social devait, à condition que cette petite bourgeoisie fût suffisamment sensible à l'évolution générale de l'époque, les rapprocher et les amener à coopérer dans un effort commun pour modifier les structures juridiques et sociales du Canada français. En réalité, il n'en sera rien. La bourgeoisie capitaliste, en majorité anglo-saxonne, lui apparaîtra d'emblée comme une rivale. En effet, celle-ci jouissait du prestige que procure la richesse, et, comme elle avait été l'artisan principal du parlementarisme, elle exerçait une influence marquante sur les structures politiques. À plus forte raison, la bourgeoisie fonctionnariste parut-elle aux professions libérales un obstacle redoutable sur la route du pouvoir politique. On comprend pourquoi les aspirations des hommes de profession canadiens-français au titre de classe dirigeante vont les 
entrainer à se représenter les capitalistes et les fonctionnaires comme une aristocratie édifiée sur les privilèges et à définir leur propre action politique d'une manière autonome. Le parti canadien et, après lui, le parti patriote 12 sont l'expression évidente de cette tendance majeure.

L'impuissance de l'Angleterre à maintenir et à solidifier, comme elle en avait l'intention en 1791, une forte aristocratie foncière, facteur de pondération et d'équilibre dans les institutions parlementaires, entrainnait infailliblement la prise du pouvoir par les classes moyennes. Sera-ce la classe capitaliste, pour qui le système parlementaire est d'abord un instrument de conquête économique, ou encore les professions libérales, pour lesquelles le parlementarisme est un outil de promotion sociale ? Les hommes de profession ne peuvent espérer assurer leur emprise sur le pouvoir qu'à condition de gagner l'appui de la masse paysanne et de se faire les promoteurs d'une interprétation plus libérale des institutions politiques. En 1792, les marchands et leurs supporteurs dominent la Chambre d'Assemblée, mais, en 1808, les notaires et les avocats, appuyés par l'habitant et le petit marchand, commandent la majorité. Il n'est donc pas étonnant qu'un radicalisme croissant se soit affirmé au niveau de la pensée politique et sociale de cette petite ou moyenne bourgeoisie.

On comprend pourquoi les politiciens canadiens-français vont aller chercher les Justifications de leurs ambitions politiques et sociales, de leurs aspirations individuelles, dans la philosophie du XVIIIe siècle. Certes, [44] pendant la phase d'apprentissage, ils s'en tiennent aux auteurs qui peuvent le mieux fourbir leur arsenal théorique : les oeuvres de Blackstone, le Traité de législation de Locke, les Lettres anglaises de Voltaire, l'Esprit des lois de Montesquieu de même que certains écrits de Rousseau. Les hommes politiques canadiens-français du temps

12 Le parti canadien et son opposé le parti breton furent les deux premières formations politiques canadiennes. Avant 1791, on avait parlé du French Party mais il ne s'agissait là que d'une coterie politique qu'on ne peut qualifier de parti. Entre 1791 et 1826, le parti canadien et le parti breton (celui des marchands) n'ont pas encore réussi à se dégager suffisamment des factions. C'est seulement après 1826 que de véritables partis beaucoup mieux structurés s'affirment dans la politique bas-canadienne. Le parti patriote, en particulier, avec son programme, sa direction, son organisation locale, ses comités a acquis la stature d'un véritable parti exigeant d'une certaine façon la solidarité des membres. Il fut aussi le premier à emprunter la notion de convention (1834). 
ne sont pas des démocrates. Comme leurs contemporains, ils affichent encore un mépris de la démocratie. Ils se rallient plutôt au libéralisme du XVIIIe siècle. Avec les philosophes, ils partagent une admiration pour les institutions britanniques. Mais leur interprétation de ces institutions prend une tonalité de plus en plus libérale. Ils désireraient une application intégrale au Canada de ce qu'ils croient être l'esprit de la constitution anglaise. Bédard parlera même, avec une certaine avance en regard de la situation du Canada, de responsabilité ministérielle. On saisit assez bien les objectifs pratiques de cette revendication qui devait livrer l'ensemble de l'appareil politique et administratif aux mains des professions libérales. Une telle concession, inacceptable à l'époque, eût écarté, si elle avait été faite, les capitalistes et les fonctionnaires en place du jeu politique. Il n'est donc pas étonnant qu'on ait accusé le parti canadien d'être démocrate. Son comportement politique et la démagogie des chefs, signes évidents des intérêts individuels et de classe que masquaient ces revendications, expliquent la violente réaction du gouverneur, des capitalistes, des fonctionnaires et du clergé catholique. 13

Mais ce n'est pas seulement au niveau politique que les idées libérales se font jour. L'esprit laïque gagne sans cesse du terrain parmi ces petits bourgeois. L'incrédulité et l'anti-cléricalisme apparaissent. Les aspirations laïques prennent de l'ampleur. L'idée d'un État neutre, gardien des droits individuels, d'un système d'enseignement neutre, fait son apparition. ${ }^{14}$ C'est que l'éducation comme l'hospitalisation apparaissent désormais à plusieurs comme des services publics. Et peu à peu se dégage, à travers les critiques contre le clergé et l'aristocratie, la conception d'un État libéral et d'une société laïque. Vers 1825, un Canadien français osera même soutenir, à une époque où les idées de liberté étaient fermement condamnées par l'épiscopat du Québec, qu'il y avait possibilité, dans l'intérêt même de l'Église, de concilier le christianisme et la philosophie libérale. 15 Évidemment,

13 La crise de 1810 ne fut pas seulement économique et politique, elle fut aussi idéologique et sociale. Voir notre texte sur « Mgr Plessis et la naissance d'une bourgeoisie canadienne », op. cit.

14 Voir notre article : «L'enseignement primaire : responsabilité des Églises ou de l'État? (1801-1836) » Recherches sociographiques, II, 2, avril-juin 1961, 171-187 ; voir aussi le recueil publié par nos soins : Papineau, textes choisis, Québec, Les Presses Universitaires Laval, 1959, 104 p. (Cahiers de l'Institut d'histoire, 1).

15 Le Canadien, 19 décembre 1821. 
cette pensée ne s'affirme pas au grand jour dans un programme cohérent. On peut la lire derrière les affirmations isolées de cette élite ; on peut aussi la déceler en toute netteté derrière [45] beaucoup d'initiatives des hommes politiques canadiens-français. Mais peut-on croire que la paysannerie aurait continué à appuyer un parti dont le programme officiel eût comporté des ferments aussi révolutionnaires ? Aussi, malgré les précautions, les tensions sont-elles allées en s'intensifiant entre le clergé et le parti canadien. En 1831-32, Papineau pourra mesurer, à l'occasion du bill des Notables, les dangers que comportait dans le contexte politique existant la promotion d'un idéal laïque.

C'est seulement après la fondation du parti patriote que se dessine un programme ouvertement démocratique ${ }^{16}$, ce que l'Église du Québec trouvera inacceptable tant du point de vue de ses convictions politiques que religieuses. Car, à ses yeux, la démocratie était essentiellement une machine à produire l'athéisme massif. Certes, les Patriotes s'inspirent toujours de Montesquieu, de l'École du droit naturel, mais d'autres influences plus particulières se font sentir : celles des radicaux anglais, de Rousseau, de Lamennais, dont on imprime sur place les $\mathrm{Pa}$ roles d'un croyant, de Franklin, de Jefferson, de Babeuf et de Tocqueville. Progressivement se dégage l'idée d'une démocratie sociale pour le Québec. Les éléments les plus radicaux du parti, dont plusieurs sont des Anglo-Saxons, veulent la séparation complète de l'Église et de l'État, l'abolition des dîmes, la disparition du système seigneurial lié au droit coutumier de même que l'abandon de la peine de mort pour vol.

S'il est vrai que les professions libérales désiraient vraiment modifier les structures sociales et politiques du Québec, comment expliquer qu'elles n'aient pas recherche le support de la bourgeoisie capitaliste ? Les hommes de profession ne pouvaient réaliser leur oeuvre de laïcisation sans cet appui. L'influence des clercs sur la masse était trop forte pour que cette petite bourgeoisie pût seule enregistrer une victoire même partielle. Une collaboration avec les capitalistes supposait cependant, en plus d'une ouverture aux réalités économiques, d'importants compromis. Il fallait pour le moment écarter l'idée d'une démocratie pour le Québec. Non seulement le peuple n'était nullement préparé à cette forme de gouvernement - il

16 Fernand OUELLET, Louis-Joseph Papineau, un être divisé, Ottawa, Les Brochures de la Société historique du Canada, n 11, 1960, 24 p. 
n'était même pas adapté au parlementarisme -, mais l'établissement d'une démocratie aurait compromis l'avenir économique du pays. Était-elle viable dans ces circonstances ? On peut aisément voir ce qu'aurait été socialement un Québec enfonce plus que par le passé dans le sous-développement. Les professions libérales n'y auraient même pas eu, au bout de quelque temps, leur place. La féodalité y aurait trouvé un terrain propice à son épanouissement. Le rapport de la commission d'enquête dirigée par Gosford est clair à cet égard : on ne peut concevoir, diton en substance, l'établissement d'une république canadienne, voire même de la responsabilité ministérielle, sans l'abandon des avantages économiques inhérents au lien [46] colonial. D'ailleurs, l'Angleterre aurait-elle accepté une solution susceptible de compromettre l'avenir du Haut-Canada? Aveugles par leurs intérêts de classe, dont la réalisation totale dépendait de la responsabilité ministérielle et de la formule démocratique, les hommes de profession ont été incapables de saisir l'importance capitale de ce compromis. Seule une minorité a vraiment songé à cette solution. Ainsi, lorsque Lafontaine, à la veille de 1837, songe à regrouper les formations politiques autour de la question de l'abolition du régime seigneurial, il vise non seulement à déloger Papineau mais aussi à établir une coalition avec les éléments capitalistes. Mais, à cette époque, l'emprise du chef patriote est trop forte pour qu'un tel projet réussisse.

Il aura manqué au Canada français d'avoir pu produire une bourgeoisie d'affaires capable de définir, en fonction d'un sain réalisme, les objectifs de la collectivité. Entre les quelques capitalistes canadiens-français de l'époque et leur société, il y avait un fossé qui les faisait apparaître comme des francs-tireurs obligés de se rattacher à une autre culture pour survivre. La faute en était, quoi qu'en disent certains historiens, à nos valeurs et à nos propres structures économiques et sociales. La faute en était aux craintes suscitées par l'essor du capitalisme commercial et financier. D'ailleurs, les ambitions personnelles de Papineau et ses visions doctrinaires allaient à l'encontre d'un compromis avec les valeurs capitalistes et bourgeoises, la seule solution viable. Pourtant, cette explication, quelque décisive qu'elle paraisse à première vue, n'est pas l'unique. Si les leaders des professions libérales se sont refusés à la seule attitude pratique susceptible d'assurer la libéralisation des structures sociales, c'est qu'ils avaient identifié leurs intérêts et qu'ils obéissaient ultimement à des valeurs beaucoup plus importantes pour eux que la mise sur pied d'une société laïque. C'est ici qu'intervient le nationalisme des pa- 
triotes. Même si le mouvement laïc a, avant 1837, fait moins d'éclat qu'il en fera par la suite, il avait singulièrement plus de force et surtout de possibilités qu'il n'en aura à l'avenir. Il puisait sa puissance dans une structure, le parti patriote, qui était en mesure de le promouvoir, dans une classe sociale et dans la faiblesse de l'Église canadienne qui n'était pas encore vraiment organisée pour la lutte. Surtout, il y avait cette possibilité, qui ne se retrouvera pas par la suite, d'un appui de la part des capitalistes anglo-saxons alors intéressés à modifier les structures sociales du Québec. La situation sera très différente après 1837.

La Révolution française provoqua, en affirmant le fameux droit des peuples à disposer d'eux-mêmes, l'éveil du mouvement des nationalités. La France révolutionnaire travailla indirectement, en dominant l'Italie, l'Allemagne et les Pays-Bas, à cristalliser des mouvements d'essence nationale. Ce principe des nationalités était, pour une part, la transposition au niveau collectif de certains aspects de la philosophie des droits individuels. C'est pourquoi, après la tourmente révolutionnaire, le Congrès de Vienne [47] veillera à réorganiser l'Europe de façon à éteindre les aspirations nationales et libérales, qui s'en trouveront par le fait même stimulées. Le Canada français du début du XIXe siècle va lui aussi s'éveiller au nationalisme. Il est certain qu'au moment de la fondation du journal Le Canadien, le nationalisme canadien-français est en voie de s'affirmer. Les années 1805 à 1810 sont capitales à cet égard. Craig, qui gouverna le Canada à ce moment, raconte que les politiciens canadiens-français ne cessent de parler de la nation canadienne et de ses libertés. Il s'agit là d'une attitude nouvelle, inconnue au XVIIIe siècle. Auparavant, il y avait eu un traditionalisme canadien-français toujours disposé à s'insurger contre les innovations, il y avait eu aussi au sein des masses paysannes une xénophobie, prompte à se manifester dans les moments difficiles, mais, dans l'ensemble, rien qui permette d'évoquer un nationalisme conscient. L'intolérance religieuse, l'attachement à la religion, à certaines valeurs traditionnelles, la crainte des étrangers, les réactions de classe, le régionalisme sont des facteurs sur lesquels un nationalisme peut s'appuyer mais ils ne constituent pas en soi l'essence de la conscience nationale.

D'ailleurs, ce nationalisme, ceci est le signe de son caractère tardif, n'est pas apparu, comme on l'a prétendu, parmi le clergé, mais au coeur même des professions libérales au moment ou elles prennent conscience de leur rôle social. Peuton croire que le clergé ou l'aristocratie foncière auraient accepté d'emblée une 
idéologie nouvelle qui pactisait avec les idées libérales, renfermait des germes de sédition et qui, en conséquence, paraissait menacer le pouvoir établi ? ${ }^{17}$ Le nationalisme a imprégné d'abord la conscience des hommes de profession parce qu'eux seuls, en raison de leurs intérêts et de leurs aspirations, étaient réellement sensibles aux situations nouvelles créées par les changements majeurs du début du XIXe siècle. Du problème de l'insertion de la culture canadienne-française dans ce nouveau contexte économique et social, ils firent un problème personnel.

La seconde moitié du XVIIIe siècle, surtout les années antérieures à 1785, avaient été caractérisées par une grande stabilité dans les structures économiques, sociales et politiques du Canada. Néanmoins, avec le temps, des évolutions s'étaient manifestées, dont on ne prendra vraiment conscience qu'au début du siècle suivant. La prospérité des années 1792 à 1802 suffisait à masquer ces cheminements. Nous avons déjà signalé le déclin progressif de la classe des seigneurs et l'introduction du parlementarisme. Il est un autre changement qui ne prendra vraiment sa signification réelle qu'après 1800 mais qui rendra difficile l'adaptation du Canada français aux réalités nouvelles. Nous voulons parler ici du déclin relatif des milieux d'affaires canadiens-français et de la prépondérance des Britanniques dans tous les secteurs de l'économie. Cette situation qu'on a attribuée à [48] tort à la Conquête est le fruit d'une évolution plutôt que d'une catastrophe qui aurait brisé les énergies individuelles et collectives. Elle était le résultat de la mentalité même du commerçant canadien-français et de son obéissance excessive aux valeurs culturelles de son milieu. L'attrait irrésistible de celui-ci pour la traite des pelleteries, sa sujétion manifeste à l'égard de l'Ouest, son individualisme étroit, une difficulté énorme à diversifier ses investissements, sa crainte de l'association et surtout son incapacité de s'adapter à l'âge des grandes corporations commerciales sont à l'origine de ce recul progressif. Au point de départ, en 1763, les commerçants canadiens-français avaient l'avantage du nombre, de l'expérience et ils possédaient en outre une richesse en capitaux aussi grande que la plupart des immigrants britanniques.

Faute d'une élite économique capable de l'entraîner dans le sens du progrès, le Canada français va prendre peur et devenir inhibé devant les événements qui se

17 Fernand OUELLET, « Toussaint Pothier et le problème des classes sociales (1829) », Bulletin des recherches historiques, 61, 4, octobre-décembre 1955, 147-169. 
produisent. Des le début du siècle, le commerce des fourrures, qui, jusque là, avait canalisé les plus forts investissements canadiens-français, entre dans une phase de décadence irrémédiable, puis naît le commerce du bois en même temps que s'affirme dans le Haut-Canada une agriculture orientée vers le marche impérial, appelée à faire concurrence à celle du Québec. Phénomène décisif, l'agriculture canadienne-française connaît, après 1802, des malaises sérieux qui débouchent sur une longue crise de structure qui affectera de plus en plus l'ensemble de la population. 18 Pourtant, la natalité conserve son rythme effarant, tandis que le nombre des terres disponibles diminue dans la même proportion. Expansion du capitalisme commercial et des institutions qui le fondent, dans une conjoncture difficile, croissance démographique étonnante, immigration massive, effondrement des rendements agraires, recul de la culture du blé, tels sont les facteurs principaux d'une situation critique qui pose des défis multiples à la conscience canadiennefrançaise lors de son éveil au nationalisme. Peut-on espérer un essor du capitalisme et une absorption des surplus de population si le Québec ne réforme pas ses techniques agricoles et ne procède pas à une révision de ses structures économiques, sociales et juridiques ? Le Canada français de l'époque fait face à une crise grave. Quelle sera son option? Entrera-t-il dans la voie du progrès ou se replierat-il douloureusement et avec agressivité sur son terroir ? Le nationalisme canadien-français sera d'abord le reflet d'une réponse négative aux impératifs de l'époque.

Les professions libérales étaient mal préparées à assumer leur rôle d'élite. Elles n'étaient pas suffisamment libérées des traditions paysannes pour admettre et apprécier l'importance des changements qui s'imposaient tant au niveau des valeurs que des institutions du Canada français. Au reste, leur formation classique et abstraite, trop appuyée sur le passé et [49] pas suffisamment accueillante au réel, avait été un pauvre instrument de promotion sociale. Aussi, les hommes de profession, dans trop de cas, faisaient-ils figure de déracinés et d'individus mal adaptés au monde bourgeois auquel désormais ils appartenaient. Il n'est donc pas tonnant de les voir se fixer sur leurs intérêts de classe et se dresser de plus en plus systématiquement contre toute évolution profonde. Même s'ils se révèlent émi-

18 Fernand OUELLET et Jean HAMELIN, «La crise agricole dans le BasCanada (1802-1837) », Rapport annuel de la Société historique du Canada, 1962, 17-33. 
nemment sensibles aux déséquilibres du temps, ils ne parviennent pas à découvrir une solution fructueuse aux problèmes concrets qui s'imposent à leur attention. Aussi la situation leur apparaît-elle sous forme de périls collectifs, intériorises d'abord par des chefs à la sensibilité maladive, en même temps que par l'ensemble de cette petite bourgeoisie et, finalement, par une portion énorme de la paysannerie. Le premier de ces périls, c'est le capitaliste anglais, c'est même le capitalisme tout court ; c'est par voie de conséquence l'anglican ; ensuite, l'Angleterre, « la marâtre », dira Papineau, et, enfin, l'immigrant. Le capitaliste anglais, perçu comme le responsable des malheurs d'une collectivité, devient alors l'ennemi à abattre, le persécuteur. Aussi la lutte doit-elle s'organiser d'une façon globale contre tout ce qui tend a affirmer l'esprit capitaliste. C'est pourquoi elle doit s'organiser en prenant appui sur les structures traditionnelles du Canada français qui, pourtant, ne renferment rien qui puisse servir de support à une société laïque et bourgeoise.

Fait paradoxal, c'est au moment où l'agriculture du Québec manifeste des signes d'épuisement que les politiciens commencent à prôner la vocation agricole des Canadiens français. Auparavant, le clergé avait certes préféré, pour des motifs moraux, l'agriculture au commerce des fourrures, mais il n'était jamais allé jusqu'à vouloir lier ses ouailles au mythe agricole. Bien aveugles, dira-t-on dans $\mathrm{Le} \mathrm{Ca}$ nadien, sont ceux qui prétendent que le Bas-Canada est appelé à devenir un pays commercial et industriel ; son avenir est inévitablement associé au premier des Arts utiles : l'agriculture. Bédard avait trop et mal lu les Physiocrates et l'Encyclopédie. Cette bourgeoisie si peu sensible aux intérêts commerciaux (ce qui ne l'empêche pas de déplorer de temps à autre le faible rôle de ses compatriotes en ce domaine) en arrive à se porter à la défense du régime seigneurial, fondement des structures agraires et désormais, croit-on, « bouclier de la nation canadienne ». 19

19 Voir Fernand OUELLET, Papineau, textes choisis ; "L'abolition du régime seigneurial et l'idée de propriété », Hermès, 14, hiver 1954, 22-36 ; F. OUELLET et J. HAMELIN, "La crise agricole dans le Bas-Canada », op. cit. M. Maurice Séguin, dans sa thèse de doctorat (encore manuscrite), a étudié le rôle du régime seigneurial comme « bouclier de la nation canadienne ». On connaît assez bien maintenant les motifs intéressés des notaires lorsqu'ils s'opposent à l'abolition du système seigneurial, aux réformes du droit coutumier, aux banques et aux bureaux d'enregistrement. Ils craignent de perdre des contrats et de voir leur situation économique empirer. On connaît les motifs des paysans et des marchands ruraux qui s'opposent à la canalisation du Saint-Laurent. Les 
Forts de toutes leurs acrobaties théoriques, [50] inventées pour démontrer que le régime seigneurial n'avait rien de contradictoire avec les institutions démocratiques, les hommes de profession dans leur ensemble se feront les supporteurs intransigeants d'un système anticapitaliste et étranger au libéralisme. Bien plus, ils voudront, dans le supposé but de le faire servir d'appui à une démocratie égalitaire, l'épurer en remettant en vigueur certaines prescriptions originelles tombées en désuétude. Adversaire d'une réforme des cadres agraires, la bourgeoisie canadienne-française s'opposera avec autant de rigidité à toute réforme du droit coutumier français. D'ailleurs, Papineau n'aura pas de difficulté à puiser dans la démocratie jacksonienne des arguments en faveur de l'abolition des banques, ces institutions opposées, criera-t-on, comme les bureaux d'enregistrement, à nos traditions morales en matière de prêt à intérêt. On connaît aussi l'opposition des patriotes à la canalisation du Saint-Laurent de même qu'à tout système de taxation qui n'atteigne pas d'abord le capitaliste. Si on saisit assez bien les avantages électoraux de ces options, on doit aussi comprendre qu'elles sont révélatrices d'un nationalisme éminemment conservateur et par-dessus tout désireux d'atteindre l'adversaire : le marchand anglais et l'immigrant.

Ce désir de protéger l'intégrité des institutions traditionnelles du Canada français apparaît aussi dans les attitudes du nationalisme à l'égard de la religion et de l'État. Même si l'incroyance fait des progrès étonnants parmi l'élite canadiennefrançaise du temps, même si l'esprit laïque ose se manifester avec vigueur en certaines occasions, on assiste cependant dans les milieux nationalistes a un curieux processus d'identification de la religion à la nation. Ainsi Papineau est libéral, démocrate, agnostique, anticlérical violent et pourtant il est convaincu que le catholicisme est un élément essentiel de notre nationalité. Par conséquent, même si des individus peuvent choisir l'irréligion, on ne peut concevoir une atteinte aux

premiers craignent le renforcement d'un concurrent, le producteur agricole du Haut-Canada, ce qui empêcherait la reprise de la culture du blé dans le BasCanada ; les seconds, qui spéculent sur la rareté du blé, craignent l'uniformisation des prix, résultat de l'abondance du ravitaillement, voire même une baisse plus marquée des prix agricoles. L'opposition aux bureaux d'enregistrement visait aussi à assurer l'expansion du droit coutumier français et du notariat dans les cantons. Au total, ces attitudes étaient dictées par le désir d'empêcher l'épanouissement du capitalisme anglo-saxon. 
privilèges de l'Église-institution et de l'Église réalité sociale de notre milieu. 20 Ici, l'accent est placé moins sur la valeur intrinsèque de la présence de l'Église que sur la religion envisagée comme un pur conformisme sociologique au service des intérêts de la nation. Si, par certains côtés, Papineau a été un des initiateurs du mouvement laïc dans le Québec, s'il a dénoncé avec force l'emprise des clercs et des institutions cléricales, il a été aussi avec beaucoup de ses contemporains un des bâtisseurs du [51] nationalisme clérical. À ce dernier titre, sa pensée annonce les idées du Français Maurras et de l'Action française, dont l'influence n'est plus à démontrer sur une portion importante de l'élite canadienne-française des années 1920 à 1930. Dans l'esprit de Papineau comme dans celui de la plupart de ceux qui le suivent, l'établissement de structures laïques dans le Québec est impensable aussi longtemps qu'une menace extérieure ou intérieure pèsera sur la nationalité canadienne-française.

Il faut bien se rendre à l'évidence. Le parlementarisme, le libéralisme et la démocratie furent avant tout des instruments servant à promouvoir les intérêts des professions libérales, lesquelles aspiraient à l'exercice sans partage du pouvoir politique, ainsi que les intérêts et les aspirations de la nation. Toutes ces formules politiques qui aboutissaient à confier l'autorité à la classe sociale qui commandait l'appui populaire, servaient éminemment bien les objectifs d'un nationalisme traditionaliste. La conception de l'État qui prévalait parmi les patriotes ne pouvait en rien, à moins qu'on eût libéralisé au préalable les institutions établies, servir la cause du laïcisme. Les milieux capitalistes étaient partisans d'un État libéral, défenseur de l'initiative privée, mais aussi d'un État capable d'investir dans l'équipement économique au gré des besoins. Quant aux patriotes, ils se rallièrent de même à une conception libérale de l'État, protecteur de l'entreprise privée et de la propriété communautaire, mais cette notion de l'État en faisait un organisme faible, soumis aux groupes de pression et tributaire des institutions locales : c'est un gouvernement complètement décentralise, abandonnant aux organismes locaux une autonomie des plus larges et ne procédant que par subventions. C'était presque la préfiguration de l'État provincial tel qu'il triomphera chez nous et par nous

20 Fernand OUELLET, « Correspondance de Papineau », dans : RAPQ, 1953-55, 1955-57, 1957-59. À plusieurs occasions, Papineau a été forcé de formuler ses positions sur cette question. Il ne l'a pas fait directement dans ses discours publics, mais ses lettres personnelles expriment clairement ces distinctions. 
après 1867. Cette représentation correspondait sans doute à une interprétation par trop fidèle des théories libérales mais elle était plus encore le fruit de l'atavisme paysan. Elle ne promettait rien de bon pour la cause du laïcisme.

Ce nationalisme de plus en plus agressif, visant après 1830 à l'indépendance du Québec, était voué à l'échec. Il avait contre lui le gouvernement, le clergé et la bourgeoisie capitaliste. Il était voué à l'échec parce qu'il était trop identifié aux ambitions de certains individus et aux intérêts d'une classe sociale qui, par ses propres forces, ne pouvait servir de moteur en vue d'un renouveau du Canada français. La régénération morale et matérielle du Canada français, dont on proclamait la nécessité urgente, ne pouvait venir de l'indépendance mais d'un renouveau profond des structures économiques, sociales et juridiques. Traduites dans les faits, les visées de ce groupe auraient signifié un retour en arrière. On ne doit pas oublier que beaucoup de paysans voulaient mettre une couronne sur la tête de Papineau. On ne doit pas oublier non plus qu'à la tête du parti patriote, il y avait un Family Compact désirant le pouvoir et l'universalisation du régime seigneurial. [52] Enfin, on doit tenir compte du fait que l'indépendance aurait coupé le Canada français de tout marché extérieur. Les aspirations laïques auraient été les premières à se dégrader dans l'intimité de notre culture traditionnelle. C'est pourquoi, même si le laïcisme a eu une quelconque autonomie, voire même une certaine vigueur avant 1837, on ne peut parler finalement de nationalisme libéral ou démocratique mais bien de national-libéralisme ou de national-démocratie. Une démocratie sans les droits de l'homme à la base eût signifié dans notre contexte la dictature de la majorité. La loi de la majorité se serait fait sentir sur les droits de l'homme comme sur n'importe laquelle autre mesure. Dans cette perspective, la Loi du Cadenas, votée sous Duplessis, est aussi démocratique qu'une autre. Si le problème de la laïcité s'était posé dans un Canada français devenu indépendant, on aurait invoqué la volonté de la majorité pour l'écarter. Il faut se souvenir que c'est une Chambre d'Assemblée dite libérale et démocratique qui refusera à Ryan, pour des motifs religieux, le droit de témoigner devant les tribunaux. 


\section{II \\ L'affirmation du nationalisme ultramontain}

$\underline{\text { Retour à la table des matières }}$

L'échec des insurrections de 1837-38 clôt une phase capitale dans l'histoire du laïcisme canadien-français. Certes, ces événements tragiques mettaient fin à certains conflits des consciences à propos de l'indépendance et du laïcisme, mais ils libéraient en même temps la voie pour l'affirmation d'un nationalisme associé intimement au jansénisme et à l'ultramontanisme.

En réalité, la réaction catholique et ultramontaine ne date pas de 1837 même si elle paraît plus évidente et plus marquée par la suite. On a pu en observer les manifestations au début du XIXe siècle sous Mgr Plessis, mais à cette époque l'Église canadienne n'était pas prête à prendre l'offensive. Elle n'était pas suffisamment armée tant sur le plan de l'organisation que de l'idéologie pour faire figure de force victorieuse. Les premiers évêques du siècle n'étaient pas encore disposés à endosser le nationalisme ou aucune idéologie trop extrémiste. Mgr Panet et Mgr Signay, bien que parfaitement conscients du rôle fondamental de l'Église et du clergé dans notre société, n'en possédaient pas moins un sens aigu du compromis et de la modération, traits assez caractéristiques de l'épiscopat de Québec au XIXe siècle. On connaît bien leurs réserves àl'endroit des méthodes d'action de Mgr Lartigue. Mais, avec ce dernier, premier évêque de Montréal, on assiste à un changement d'attitude et de stratégie. C'est la contre-offensive des clercs qui s'organise. Cousin de Papineau et des Viger, avocat lui-même, le futur évêque de Montréal n'avait pas les mêmes préventions que ses prédécesseurs [53] à l'endroit du nationalisme. Il s'agissait tout simplement de détacher le nationalisme de son contenu libéral et d'en faire le principe d'une société catholique et cléricale. ${ }^{21}$

21 La querelle pour l'érection de l'évêché de Montréal, dont Mgr Lartigue fut un des principaux acteurs, a créé une situation favorable à l'expression de tendances nationalistes au sein du clergé. Ce fut en un sens une lutte opposant le clergé canadien-français aux Sulpiciens, Français d'origine. Ce conflit mobilisa la plupart des groupements sociaux et politiques. On sait que les patriotes 
Mgr Lartigue apparaît, peut-être après Mgr de Laval, comme le premier évêque ultramontain. Son tempérament qui ne se satisfaisait pas des demi-mesures le prédisposait sans doute à être l'homme de la contre-révolution. On sait déjà quel choc révélateur produisit en lui, lors de son premier voyage en Europe, la lecture de l'Essai sur l'indifférence de Lamennais. ${ }^{22}$ S'il fut transporté d'enthousiasme par le génie de Lamennais, il fut davantage influencé par les oeuvres de De Bonald et de De Maistre, ces deux protagonistes de la monarchie absolue et d'un idéal théocratique médiéval destiné à abolir définitivement tous les vestiges de la Révolution française. En quittant une France qui évoquait pour lui le souvenir de la Révolution, Mgr Lartigue écrivait: «J'ai quitté avec plaisir le volcan de la France impie, pour entrer sur la terre pacifique d'Angleterre ». ${ }^{23}$ On comprend pourquoi l'évêque de Montréal, à l'instar des théocrates français, a eu tendance à identifier catholicisme à monarchie, déisme à libéralisme et athéisme à démocratie. Ainsi, lorsqu'il qualifie la démocratie américaine « d'état pire que la barbarie », il se réfère nettement à ces schèmes d'interprétation.

Sous Mgr Lartigue, la réaction catholique et ultramontaine porte des desseins bien précis. La société canadienne-française, étant composée en très grande majorité de catholiques, doit accepter le clergé non seulement comme son guide religieux et moral mais aussi dans le domaine temporel. Non seulement l'Église se doit de travailler à maintenir tous ses privilèges passés mais aussi de chercher à renforcer son rayonnement social, idée chère aux théocrates sociaux de la Restau-

prirent parti pour Mgr Lartigue. En 1830, les critiques s'accumulent sur le collège des Sulpiciens auquel on reproche entre autres de ne pas donner une éducation nationale alors que le collège de Saint-Hyacinthe apparaît comme un foyer d'éducation nationale. Le nationalisme ne se généralise cependant parmi le clergé qu'après 1840. Un texte de l'abbé Tétrau, de Saint-Hyacinthe, est significatif à cet égard : "À moi catholique, homme de conviction, à moi qui regarde le catholicisme comme la sauvegarde la plus certaine de notre nationalité, à moi, dis-je, il ne reste plus qu'un voeu à former c'est que nos hommes politiques soient toujours en bon rapport avec le clergé catholique » (APQ, Lettre de 1847).

22 «Cet ouvrage par l'énergie de ses pensées, la profondeur de ses raisonnements, et la force de son élocution est digne de faire époque dans les Annales du Christianisme » (APQ, Journal de Mgr Lartigue, 156).

23 Ibid., 123. Nous avons traité, dans un article sur son mandement de 1837, de "Mgr Lartigue et la réaction libérale », Bulletin des recherches historiques. 58, 2, 1952, 97-104. 
ration. Aussi les élites laïques se doivent-elles de travailler sous l'égide de l'Église à établir les bases de cette orientation. C'est dans cette perspective que le domaine de l'enseignement 54] prend une signification vitale pour l'évêque de Montréal. 24 D'ailleurs l'urgence d'une intervention ne lui faisait aucun doute. Après 1800, 1'État avait commencé à assumer des responsabilités dans ce secteur ; à partir de 1829, la loi des Écoles de l'Assemblée ne se contentait pas de reconnaître les droits de l'État, elle portait en elle des objectifs masqués mais évidents de laïcisation. Ce n'est pas à l'enseignement nationaliste que l'évêque de Montréal en veut, c'est à la neutralité. Autre phénomène inquiétant pour Mgr Lartigue: le faible nombre des effectifs cléricaux disponibles pour l'enseignement primaire avait favorisé une certaine primauté numérique de l'instituteur laïc. Toutes ces orientations furent perçues sous forme de dangers qu'il fallait à tout prix écarter de façon à restaurer les droits intangibles de l'Église. Aussi Mgr Lartigue mena-t-il une lutte sans merci contre l'Institution royale et les écoles de l'Assemblée. C'est à lui qu'on doit ce projet de remplacer les laïcs adonnés à l'enseignement par des congrégations enseignantes. De là ses efforts pour susciter l'immigration de Frères et de communautés de femmes. Le non-renouvellement de la loi des Écoles de l'Assemblée en 1836 était en partie un triomphe personnel ; la faillite d'un projet d'École normale, peu conforme aux bons principes, est aussi son oeuvre. La réaction catholique, dont l'évêque de Montréal fût le principal artisan, s'était retrempée aux sources de la Restauration. Si elle fut cause d'un renouveau religieux dans la société canadienne-française, elle marqua en plus une reprise de contact avec l'esprit sectaire et le fanatisme. Ce mouvement de réaction n'aura pas de difficulté à se gagner de plus en plus l'appui des masses et de la bourgeoisie.

24 Voir : «L'enseignement primaire : responsabilité des Églises ou de l'État? (1801-1836) », op. cit. Un texte illustre bien la rigidité des normes ecclésiastiques même sous le régime des Écoles de l'Assemblée : «J'apprends que des maîtres d'écoles de votre paroisse font l'instruction des filles et même les enseignent mêlées avec les garçons : apprenez-leur, ainsi qu'aux parents et aux enfants, que l'un et l'autre sont opposés à toutes les règles; et qu'on ne peut absoudre ceux d'entre eux qui s'obstinent dans ce grave péché » (Mgr Lartigue au curé Chèvrefils, 13 mai 1830 : RAPQ, 1942-43, 198). Ce texte permet de saisir les difficultés qui se dressaient face à l'épanouissement d'un laïcat masculin dans l'enseignement : esprit clérical envahissant, décalage du salaire entre l'instituteur et l'institutrice, idée que les femmes sont plus religieuses que l'homme, enfin cette norme adoucie avec le temps en faveur des femmes mais beaucoup moins vite pour les hommes. 
Grâce à l'esprit militant et aux efforts incessants de Mgr Lartigue, l'Église aura désormais en main les moyens d'informer toujours davantage de sa présence tous les secteurs de la vie collective. Elle a maintenant un programme, des objectifs puissants, un journal de combat, Les Mélanges religieux; elle peut agir sur la presse et elle s'inscrit avec de plus en plus de force dans l'enseignement. Certes, l'ultramontanisme est plus ou moins, selon les individus et les groupes, l'article de foi des clercs, dont certains échappent encore à son emprise, mais les ultramontains sont des doctrinaires et des combatifs. Leur zèle est inlassable et leurs craintes toujours présentes. Ils ont des chefs vigoureux qui ne craignent pas de s'affirmer. Mgr [55] Bourget et Mgr Laflèche 25 font figure de leaders incontestés. L'immigration de religieux français de même que l'accélération étonnante sur place des vocations sont en même temps l'indice de la vitalité de l'Église et l'explication de ses triomphes successifs. L'Église a l'immense avantage de s'appuyer sur des institutions d'une fermeté inébranlable : le Collège, l'école, la paroisse et la famille. Elle est à l'origine de beaucoup de mouvements religieux et autres auxquels elle livre son empreinte. Dès lors on comprend le renforcement progressif de son emprise sur la société canadienne-française de la seconde moitié du XIXe siècle. C'est l'âge d'or de l'influence des Veuillot, De Bonald et De Maistre et de tous les théocrates plus ou moins talentueux. De là cette méfiance généralisée àl'endroit du rôle social du laïc, qu'il soit dans l'Église ou en dehors. C'est pourquoi le laïcisme comme le libéralisme sont l'objet d'une hostilité profonde. Pourtant ce ne sont pas là des attitudes supportées plus ou moins ouvertement par tous les ecclésiastiques. Un certain esprit libéral a pénétré assez profondément dans certains milieux, lequel se traduit par un sens vrai de la modération et par une certaine reconnaissance du rôle du laïc et de l'État. L'abbé Verreault et le cardinal

25 Mgr Laflèche, alors qu'il n'était que simple prêtre, a publié un petit livre dans lequel sont consignées ses croyances politico-religieuses. Ses positions sont beaucoup plus nuancées que celles de ses prédécesseurs en ce domaine : il ne condamne pas d'une façon absolue les gouvernements aristocratiques et démocratiques; il n'est pas non plus le partisan d'une monarchie absolue. La forme de gouvernement la plus parfaite est la monarchie tempérée et la moins parfaite est la démocratie. Il accepte cependant le système parlementaire avec ses exigences. On voit déjà dans ce livre une horreur du libéralisme de même qu'on y voit exprimées ses croyances ultramontaines et théocratiques. (Quelques considérations sur les rapports de la société civile avec la religion el la famille, Montréal, 1866, 268 p.). 
Taschereau en sont des exemples. Non seulement on décèle derrière beaucoup d'attitudes la marque indiscutable du catholicisme libéral mais aussi celle du catholicisme social. Il reste cependant que le courant théocratique associé au nationalisme agraire a prévalu, de sorte que les idéaux et les objectifs pratiques du premier évêque de Montréal sont presque devenus avec le temps des réalités globales. Il est à noter cependant qu'avant la Confédération, l'État ne pouvait être un instrument docile au service de l'Église. De là les possibilités, au reste limitées, d'expression d'un mouvement de caractère libéral et laïc.

Après 1837, le nationalisme à tendance cléricale pénètre davantage les professions libérales. Celles-ci continuent à croître même après 1873 à un rythme renversant mais, par contre, elles parviennent peu à peu à s'insérer dans les structures politiques et sociales du Québec et du Canada. De même, en dépit d'une grande sensibilité au vieux mythe agricole, elles ont appris sous l'égide de Lafontaine et de Cartier à composer avec les grands intérêts commerciaux, industriels et financiers. La puissance même de ces intérêts en regard de la politique et l'omnipotence du patronage invitaient à la collaboration plutôt qu'a l'obstruction. Il faut dire aussi que le [56] parti conservateur, réalité presque permanente de notre existence politique à cette époque, offrait de sérieuses garanties aux tenants de l'ultramontanisme aux prises avec le libéralisme doctrinaire et le péril démocratique. C'est dans cette perspective à la fois sociale et idéologique, à quoi il faut ajouter la crainte de la démocratie américaine, que se comprend la sensibilité de l'élite canadienne-française au courant unitaire qui appelait la Confédération et la création d'un gouvernement central fort. C'est par ce biais fait d'intérêts et de valeurs que les appels à l'unité canadienne seront entendus par les nationalistes du Québec. Seule une minorité agissante échappera à ce message. 26

Certes, il règne toujours une grande instabilité chez les professionnels et les marchands locaux mais la prospérité, du moins jusqu'en 1873, favorise la majorité. 27 Aussi cette bourgeoisie paraît-elle dans son ensemble beaucoup plus

26 Nous avons parlé de cette évolution dans notre texte sur «Les fondements historiques de l'option séparatiste dans le Québec », Canadian Historical Review, XLIII, 3, September 1962, 185-203.

27 Voir L'Avenir où se reflète la saturation des professions libérales. Il reste néanmoins que la prospérité des années 1850-1873 a apporté, du moins à long terme, de nombreux correctifs à cette situation. 
conservatrice qu'auparavant. En France, un phénomène analogue se produit parmi la bourgeoisie qui, face à la montée du syndicalisme et du socialisme, s'appuie à la fois sur l'État et sur l'Église. Entre les années 1840-50 et par la suite, on observe au Canada français l'existence des mêmes craintes. Si notre bourgeoisie craint le renforcement de l'appareil étatique, elle craint tout autant l'affirmation de l'élément ouvrier. Pourtant nous ne formions pas alors une société industrielle. Dès 1850, le danger socialiste, voire même communiste, préoccupe beaucoup d'esprits. C'est pourquoi les hommes de profession sont devenus les défenseurs de la propriété privée et de l'acception libérale de l'État. S'ils avaient supporté les structures laïques avec autant d'ardeur qu'ils ont défendu la propriété capitaliste, le problème du laïcisme se poserait aujourd'hui en des termes tout différents. C'est pour conjurer ces périls et certaines incertitudes du temps que la bourgeoisie s'est rapprochée davantage de l'Église, facteur d'ordre et de stabilité sociale. À l'origine de cette option, on découvre bien le renouveau catholique propre à cette époque, mais il faut y voir plus précisément l'influence du conformisme ultramontain et nationaliste. La religion y est davantage un phénomène collectif et national qui s'impose aux consciences individuelles. Elle risque par conséquent dans cette optique, d'enlever toute autonomie et toute puissance créatrice à la conscience individuelle, de l'ancrer dans l'automatisme de la tradition. 28 Dès lors, la [57] majorité de ces bourgeois se désolidarisent des tendances laïcisantes, plusieurs entreprennent même une lutte féroce contre le libéralisme doctrinaire et toutes les formes de libre-pensée. Une véritable obsession de la franc-maçonnerie se déchaîne. Trudel, celui qu'on a surnommé le Grand Vicaire, et Tardivel sont les prototypes de cette bourgeoisie ultramontaine, janséniste et traditionaliste. ${ }^{29}$ Au fond, le

28 Abbé A. MAILLOUX, Manuel des parents chrétiens ou devoirs des pères et mères dans l'éducation religieuse de leurs enfants, Québec, 1851, 328 p. Ce livre a exercé une influence profonde à 1'époque. Il s'inscrit à la fois dans une tradition et dans l'effort de renaissance religieuse du temps. Il pose cependant avec acuité le problème de l'autonomie et de la liberté de la conscience individuelle. Donner à l'enfant «l'habitude de la foi » est une des grandes préoccupations de Mailloux.

29 Laurier L. LAPIERRE, « Joseph-Israël Tarte : Relations between the FrenchCanadian Episcopacy and french-Canadian Politicians (1894-96) », Report 1958, Canadian Catholic Historical Association, 23-38. 
dessin de cette évolution explique la défaite inévitable de l'Institut canadien ${ }^{30}$ et le sort du laïcisme au sein du parti libéral. Encore une fois, notre nationalisme, en raison de ses rapports étroits avec la religion comme fait collectif, aura raison des visées laïcisantes.

En 1844, naît un mouvement de caractère littéraire et politique appelé à livrer de durs combats : l'Institut canadien de Montréal. Cet organisme n'était pas la première association de ce genre. Entre 1834 et 1837, trois sociétés aux buts à peu près similaires avaient été fondées à l'ombre du parti patriote : la Société SaintJean-Baptiste, la Société "Aide-toi et le Ciel t'aidera », Les Fils de la liberté. Toutes trois étaient libérales et nationalistes à l'origine, mais seule notre «société nationale »traversera sans encombre la tourmente révolutionnaire. Mais à quel prix ? Au prix de l'abandon pur et simple de ses tendances radicales. Il ne pouvait donc être question de faire servir cette organisation patriotique à un renouveau de la vie littéraire et politique, tel que l'entendraient désormais les membres de l'Institut canadien de la métropole. L'Institut eut de lents départs : il fallut recruter des membres, établir des cadres, édifier une bibliothèque, élaborer un programme d'action, faciliter les rencontres, les discussions et stimuler les travaux. Trois ans après sa fondation, l'association se donne un medium de publicité en fondant le journal L'Avenir. Plus tard, elle pourra compter sur Le Défricheur et Le Pays. Quant à La Minerve, l'ancien porte-parole des patriotes, elle sert maintenant d'autres causes moins dangereuses.

Les animateurs de l'Institut et de L'Avenir en arrivent assez vite à mettre sur pied un programme d'action, préconisant pour le Québec la laïcité intégrale : séparation totale de l'Église et de l'État, neutralité de l'enseignement à tous les niveaux, à l'exception de quelques collèges pour la formation des clercs, reconnaissance absolue des droits individuels. Ils ne se contentent pas de revendiquer, ils dénoncent les confusions qui existent dans les structures. Ces libéraux puisent dans la philosophie du XVIIIe siècle les fondements théoriques de leurs appels à la liberté, à la tolérance. Ils y découvrent en plus un arsenal critique bien au point. Il reste cependant [58] que leur libéralisme avait une tonalité et une justification

30 Voir sur cette question de l'Institut canadien : Marcel TRUDEL, L'influence de Voltaire au Canada, op. cit., vol. II. La collection Papineau-Bourassa renferme des correspondances extrêmement intéressantes sur le mouvement libéral après 1850. 
très contemporaines. Ils connaissent bien les oeuvres des libéraux et des démocrates français de l'époque. Bien plus, les conquêtes libérales du siècle les stimulent et servent de précédents à leur action. Ainsi, on ne saurait nier l'influence profonde sur eux de la question italienne qui les préoccupait au même titre que les ultramontains. On peut dire que l'apport de Lamennais à leur pensée est pour le moins aussi marqué que celui de Voltaire et de l'Encyclopédie.

Le laïcisme des membres de l'Institut canadien, même s'il colle parfaitement bien à l'ensemble du mouvement libéral européen, se revendique aussi du gallicanisme des gens de robe du XVIIIe siècle. On pourrait croire que ces libéraux, catholiques ou non, n'ont posé le problème des structures cléricales et proposé la solution laïque que parce qu'ils avaient subi l'influence européenne, autrement dit parce qu'ils avaient lu de mauvais livres. Pourtant, plusieurs avaient pris contact avec le socialisme français mais aucun d'eux n'était devenu socialiste. Ce serait simplifier grossièrement les choses que d'accepter cette explication traditionnelle. En plus de correspondre à une prise de conscience amorcée depuis longtemps dans le milieu canadien-français, la question de la laïcité s'établissait par rapport à une situation qui exigeait une redéfinition du rôle de l'Église et des clercs dans la société. Catholiques et protestants étaient parqués dans des cadres définis à une époque où l'union de l'Église et de l'État était le seul principe reconnu. Quant aux autres, ils devaient se conformer à cette situation.

D'ailleurs, depuis le début du siècle, on avait déploré le manque d'adaptation de l'Église à une société qui se modernisait. Ainsi, l'introduction du parlementarisme supposait de la part de l'individu de nouvelles attitudes politiques; mais l'enseignement des collèges ne parlait encore que de monarchie de droit divin, de soumission que le sujet devait au pouvoir établi et de primauté de l'Église. Ce manque d'adaptation au monde moderne débouchait avec la grande offensive ultramontaine sur des attitudes de plus en plus réactionnaires. Ce n'est pas seulement le non-croyant qui subissait le contre-coup de structures cléricalisées à outrance mais aussi les catholiques éclairés. On a reproché à ces libéraux une virulence peu commune, un fanatisme puissant. N'était-ce pas d'abord une réponse à la virulence et au fanatisme des ultramontains ? Indépendamment de ces excès et en dépit de ses faibles chances de réussite, on peut dire que la présence de ce courant libéral était nécessaire. S'il ne provoqua pas par ses appels à la liberté un changement dans les institutions, il fut avec l'État un facteur indiscutable d'équili- 
bre, dans la mesure où la vague ultramontaine pouvait être endiguée. On comprend pourquoi l'Institut va susciter la méfiance de l'épiscopat et provoquer un conflit qui signifiera sa perte. La question de l'Index et la fameuse affaire Guibord devaient poser à la conscience collective le problème global de la laïcité. Mais une victoire légale acquise en faisant appel à des [59] traditions étrangères à notre milieu ne pouvait rallier l'opinion publique. Les Dessaulles et Doutre jetèrent toutes leurs forces dans ces deux batailles. Dès lors, on vit clairement que l'Institut canadien ne rejoignait qu'une minorité, au reste fort vulnérable.

Les catholiques libéraux ne résisteraient pas aux condamnations fulminées par l'évêque de Montréal. De même existaient à l'intérieur de l'Institut une multitude d'options politiques et nationalistes. Cette diversité des engagements individuels provoqua des tensions et des défections. Mais il y avait beaucoup plus. Le mouvement laïc ne rejoignait qu'une fraction des professions libérales et il ne commandait pas l'appui d'une classe comme telle. Le mouvement de l'Institut canadien avait inspiré momentanément beaucoup de jeunes et attiré les éléments les plus instables des professions libérales. C'était là un facteur de désintégration. Enfin, cette révolte laïque n'avait le support d'aucune formation politique capable de prendre le pouvoir et de s'y maintenir. Le groupe des rouges n'était pas une réalité permanente de la vie politique. En réalité, ce mouvement n'est parvenu à durer que grâce aux convictions fermes d'une minorité combative, assez bien pourvue financièrement, bien armée sur le plan idéologique, profondément anticléricale mais parfaitement consciente de la nécessité d'une libéralisation des cadres et des mentalités.

Après 1874, les luttes restent vives mais on a la ferme impression que le déclin du courant libéral est entré dans sa dernière phase. Des individus reprennent la lutte, tentent de bâtir un mouvement : c'est peine perdue. Les journaux au service de cette cause disparaissent presque aussi vite qu'ils naissent. Les aventures de Buies et de Filiatrault en sont des exemples frappants. Il reste cependant que le parti libéral demeura le dernier refuge de ceux qui croyaient en la laïcité. Pendant ce temps, le nationalisme conservateur ou ultramontain gagnait sans cesse du terrain. Associé au parti conservateur qui domina en gros la politique canadienne de 1876 à 1896 ou indépendant comme celui de Tardivel, il se prépare des lendemains triomphants. 
On peut se demander si le parti libéral, soit le fédéral ou le provincial, pouvait alors servir de moteur efficace à un mouvement laïcisant. Disons de prime abord que la conjoncture ne lui était pas tellement favorable. Ses options économiques, en particulier son libre-échangisme, les tendances annexionistes de beaucoup de ses membres de même que ses objectifs de laïcisation l'empêchaient de s'incruster avec fermeté dans la politique canadienne. C'est précisément pour arriver à se gagner la faveur populaire que le parti libéral fédéral se résoudra à adopter des positions plus souples et plus réalistes. La sagesse politique exigeait même qu'un parti de caractère national abandonnât aux formations politiques provinciales le soin de reformer les institutions locales du Québec. On comprend moins dans cette perspective l'évolution du parti libéral provincial qui, en même temps qu'il [60] se dégage du libéralisme doctrinaire, s'oriente vers un nationalisme conservateur ou modéré selon les circonstances.

Cette évolution se précise d'une façon très nette après l'affaire Riel en 1885. Le parti libéral du Québec s'éprend d'autonomie et se révèle de plus en plus sensible aux oscillations de l'opinion publique. Ainsi, lorsque Laurier arrive au pouvoir en 1896, les tendances libérales sont au plus bas. Il y aura bien jusqu'à la seconde guerre mondiale quelques francs-tireurs pour entonner l'hymne de la laïcité ; mais il n'y a personne qui réponde. Aux anciennes influences ultramontaines s'ajouteront bientôt celles de Maurras, de Barrès et de l'Action française. Notre nationalisme s'en pénètre et ainsi s'expriment moins ouvertement qu'autrefois mais plus profondément l'opposition aux idées laïques et un mépris certain de la démocratie. Le conservatisme et la puissance des grandes corporations cléricales et professionnelles semblaient garantir pour longtemps le statu quo au moment de la mise en place d'une société industrielle. Quant à l'État, de plus en plus tributaire des groupes de pression et répugnant à intervenir directement dans l'activité économique et sociale, il n'était qu'un pauvre instrument de promotion de la laïcité. Restait une bourgeoisie d'affaires sans grande force, sans cohésion et toujours imbue des valeurs traditionnelles qui servaient ses intérêts et son besoin de prestige. C'est pourquoi la période de la grande crise signifiera, en dépit de certains cheminements en cours, l'effacement maximum des tendances laïcisantes.

\section{Fin du texte}

